\title{
Fatigue design of lattice materials via computational mechanics: application to lattices with smooth transitions in cell geometry
}

\author{
Ehsan Masoumi Khalil Abad, Sajad Arabnejad Khanoki, Damiano Pasini ${ }^{\text {t* }}$
}

Ehsan Masoumi Khalil Abad: PhD candidate, Mechanical Engineering Department, McGill University, Montreal, Quebec, Canada. Email: ehsan.masoumikhalilabad@mail.mcgill.ca

Sajad Arabnejad Khanoki: PhD candidate, Mechanical Engineering Department, McGill University, Montreal, Quebec, Canada. Email: sajad.arabnejadkhanoki@mail.mcgill.ca

Damiano Pasini: Associate Professor, Mechanical Engineering Department, McGill University, Montreal, Quebec, Canada. Email: damiano.pasini@mcgill.ca

\footnotetext{
${ }^{\dagger}$ Corresponding author. Tel: +1 514398 6295; Fax: 514398 7365; Email: damiano.pasini@ mcgill.ca $\$$ Both PhD students were equally involved and contributed to this work.
} 


\begin{abstract}
A numerical method based on asymptotic homogenization theory is presented for the design of lattice materials against fatigue failure. The method is applied to study the effect of unit cell shape on the fatigue strength of hexagonal and square lattices. Cell shapes with regular and optimized geometry are examined. A unit cell is considered to possess a regular shape if the geometric primitives defining its inner boundaries are joined with an arc fillet, whose radius is $1 \%$ of the cell length. An optimized cell shape, on the other hand, is obtained by minimizing the curvature of its interior borders, which are conceived as continuous in curvature to smooth stress localization.

For a given multi-axial cyclic loading, failure surfaces of metallic hexagonal and square lattices are provided along with their Modified Goodman diagrams to assess the effect of mean and alternating stresses on the fatigue strength. In good agreement with the experimental data available in literature, the numerical results show that the shape of the unit cell has a major impact on the fatigue performance of the lattice material. For example under fully reversible tension, the fatigue strength of optimized square lattices of $10 \%$ relative density is shown to be $54 \%$ higher than that of their conventional counterparts with regular cell geometry.
\end{abstract}

\title{
1. Introduction
}

A lattice material is a cellular material with a periodic arrangement of cells in either two or three dimensions. Besides mechanically superior to any other material [1-3], lattice materials have been shown to be attractive for their multifunctional properties, e.g. thermal insulation, sound resistance and shock energy damping, and thus to be of potential use in a broad range of applications, including battery electrodes, catalyst supports, vibration insulators, jet-engine nacelles, ultra lightweight sandwich panels, and biomedical implants, [3-8]. 

recurring waves on a ship hull, the aero-acoustic excitation of a turbine engine, and the rhythmic forces acting on an orthopedic implant during the swing phase of walking are all classical examples of time-dependent loads [9-14]. A cyclic load has generally a detriment impact on the resistance of the lattice material. Factors that govern fatigue failure are not limited to the alternating and mean stresses, load frequency, environment conditions, and macroscopic form of the structure, but include also the geometry of the microstructure, i.e. the geometry in which the unit cell of the lattice is shaped. If geometric discontinuities are embedded at either the macro or/and the micro scale, then a severe drop in the fatigue resistance is observed.

From literature, it appears that the study of fatigue failure in cellular materials, with both random (foam) and periodic arrangement of cells (lattice), has received less attention than their monotonic quasi-static and dynamic properties [8, 15-21]. Among the investigations, both experimental and theoretical approaches have been developed for metallic and polymeric cellular materials under fatigue conditions. The experimental works are predominant and mainly stem from studies on foams [22-29], which aim at determining the stress-life curves under shear and axial loadings. For example, Burman [28] experimentally characterized the fatigue behavior of sandwich panels with polymeric PVC and PMI foam cores. The effect of the alternating strain on the fatigue life of polymeric cellular materials was shown to be more significant than that of the mean stress. It was also observed that reversible cyclic loadings, with negative max to min stress ratio, drastically reduce the fatigue resistance of polymeric foams. In another work, closed-cell aluminum alloy foams, Alulight and Alporas, were tested under alternating loads of fracture mode I to measure their fatigue resistance to crack propagation [29]. Crack evolution was observed to be controlled by linear elastic fracture mechanics. On the other hand, due to the high sensitivity of the crack propagation rate to the alternating stress intensity, the conventional 
damage-tolerant methodology was found to be inappropriate for use in the fatigue design of aluminum foams. McCullough et al. [30] observed that ratcheting in closed cell Alulight foam is the dominant cyclic deformation mode for a tension-tension and compression-compression load. In another study on crack propagation, Motz et al. [31] experimentally showed that a cellular solid with hollow spheres made of a stainless steel (316L) has fatigue strength $50 \%$ to $60 \%$ lower than that of a closed cell aluminum foam. Such strength reduction was attributed to the presence of stress concentration at the bonding points between spheres.

Studies on the fatigue of lattice materials are even less than those on foams. On the experimental side, Côté et al. [9], among few researchers, characterized the stress-life curves of sandwich panels with a lattice core made of stainless steel. Sandwich panels with a unit cell of diamond shape have been observed under alternating shear weaker than under axial load. A fatigue collapse map was generated for stainless steel sandwich beams with pyramidal core [10] and crack nucleation sites leading to failure were identified in the micro structure. Under cycling loading it was shown that the brazed joints are the weakest points of the panel core, hence their effect is to significantly reduce the shear fatigue strength. In another study, Côté et al. [11] examined the available experimental data for metallic lattice and foam cores and showed that the fatigue to monotonic strength ratio, $\Delta \bar{\tau}_{e} / \tau_{u t t}$, are close to 0.3 and 0.2 , respectively, for $\mathrm{R}=0.1$ and $R=0.5$. The data, gathered from a wide range of lattice cores, suggested that the fatigue to monotonic strength ratio generally does not depend on core topology, relative density, and material properties.

On the theoretical side, empirical relationships of finite/infinite life as well fracture mechanics approaches have been employed to predict the fatigue life of a periodic cellular solid [32-34]. In these studies, the cell walls were assumed to flex like a beam. However, as observed by Simone et al [35], the use of beam elements, rather than continuum elements, such as plane elements, is 


\section{Fatigue design methodology}

Infinite-life, safe-life, fail-safe, and damage-tolerant criteria are well-established approaches for the design of a material against fatigue fracture and degradation. Each method requires specific properties to characterize the material behavior under fatigue. Certain properties, e.g. the 
endurance limit, can be generally obtained from traditional approaches, e.g. the stress (strain)-life method, other can determined though more recent techniques based on fracture mechanics. The stress (strain)-life method introduced by Wholer is one approach that provides the number of cycles that a smooth test specimen can resist under alternating stresses (strains) of constant amplitude before fracture. The Wholer's strain-life curves help to gain insight into the influence of the number of cycles on the alternating stress, but they fail to capture the detrimental effect of the mean stress. For this purpose, other methods have been proposed. One of these is the constant-life diagram (Figure 1), which is constructed by curve fitting of experimental data for various combinations of stress amplitudes and mean stresses. Goodman, Soderberg, Gerber, and modified Goodman are the most common curve fitting models.

In this work, we develop the modified Goodman diagrams for lattice materials [36] under high cycle fatigue loading. We assume the specimen to be free of damage, since the endurance limit is very sensitive to the specimen conditions, such as scratches, notches and nicks [36]. As shown in Figure 1, the material properties necessary to generate the diagram are: yield strength, ultimate strength and fatigue strength for a given life, or endurance limit for materials with infinite life. Once these properties are determined, the diagram can be constructed (Figure 1) from the intersection of i) the line connecting the material ultimate and fatigue strengths for a given life with ii) a $45^{\circ}$ degree sloped line, originated from the monotonic yield strength of the material. To extend the application of the modified Goodman model to planar lattice materials, we assume the reference lattice material be free of defects. We also assume that the cell wall material is a continuum media with properties comparable to those of its bulk material, which means that the material has one level of structural hierarchy. This hypothesis sets the limit of applicability of the proposed method to a minimum length-scale that depends on the material microstructure, slip system, grain and size [37-39]. If the effect of nanostructure defects, grain and size of the 
material, has to be modeled, then two length scales in the lattice microstructure should be considered, as described by Zienkiewicz and Taylor [40].

Next section describes how to obtain the properties required to generate the modified Goodman diagram. For this purpose, asymptotic homogenization theory, one among other homogenization approaches $[2,4,15,21,41]$, is chosen here and implemented in a computational framework, since its mathematical foundation has been proved together with its capacity to accurately capture the real stress distribution within the cell walls of a lattice.

\subsection{Homogenized strength of lattice materials}

The analysis of a lattice material is often performed by isolating a representative volume element (RVE) and calculating its properties, which under certain assumptions represent the homogenized properties of the macro material. Theoretical, numerical, and experimental approaches can be used to homogenize the properties of a lattice $[2,15,16,42-52]$. Here, we use asymptotic homogenization to determine its effective mechanical properties, including the effective stiffness, yield and ultimate strength. Besides the linear elastic terms [53, 54], we model also the effect of material non-linearity as a result of plastic deformation $[55,56]$. Asymptotic homogenization allows obtaining the macroscopic stresses that lead to the microscopic yield, or fracture, as well as the endurance limit of the lattice. While in this work the method is demonstrated with reference to two common loadings, i.e. in-plane uni-axial and pure shear loadings, yield surfaces are also provided for the fatigue design of lattice materials under any combination of load.

The underlying assumption of asymptotic homogenization is that each field quantity depends on two different scales: one on the macroscopic level x, and the other on the microscopic level, $\mathrm{y}=\mathrm{x} / \varepsilon$, where $\varepsilon$ is a magnification factor that scales the dimensions of a unit cell to those of the 
material at the macroscale. In addition, the field quantities, such as displacement, stress, and strain are considered periodic at the microscale and assumed to vary smoothly at the macroscopic level $[47,53]$.

Under the assumption of small deformation, the standard weak form of the equilibrium equations for a cellular body $\Omega^{\varepsilon}$ with the pertinent geometrical details of voids and cell wall is by [53]

$\int_{\Omega^{\varepsilon}}\left\{\varepsilon^{0}(v)+\varepsilon^{1}(v)\right\}^{T}[\mathrm{E}]\left\{\bar{\varepsilon}(u)+\varepsilon^{*}(u)\right\} d \Omega^{\varepsilon}=\int_{\Gamma_{t}}\{\mathrm{t}\}^{T}\{\mathrm{v}\} d \Gamma$

where $[E]$ is the local elasticity tensor that depends on the position within the RVE, $\left\{\varepsilon^{0}(v)\right\}$ and $\left\{\varepsilon^{1}(v)\right\}$ are the virtual macroscopic and microscopic strains, respectively, $\{\bar{\varepsilon}(u)\}$ is the average or macroscopic strain, $\left\{\varepsilon^{*}(u)\right\}$ is the fluctuating strain varying periodically at the microscale level, and $\{\mathrm{t}\}$ is the traction at the traction boundary $\Gamma_{t}$. Being the virtual displacement, $\{\mathrm{v}\}$ may be chosen to vary only on the microscopic level and be constant on the macroscopic level. Based on this assumption, the microscopic equilibrium equation can be obtained as

$$
\int_{\Omega^{\varepsilon}}\left\{\varepsilon^{1}(v)\right\}^{T}[\mathrm{E}]\left\{\bar{\varepsilon}(u)+\varepsilon^{*}(u)\right\} d \Omega^{\varepsilon}=0
$$

Taking the integral over the RVE volume $\left(V_{R V E}\right)$, equation (2) may be rewritten as

$$
\int_{V V_{R V E}}\left\{\varepsilon^{1}(v)\right\}^{T}[\mathrm{E}]\left\{\varepsilon^{*}(u)\right\} d V_{R V E}=-\int_{V V_{R V E}}\left\{\varepsilon^{1}(v)\right\}^{T}[\mathrm{E}]\{\bar{\varepsilon}(u)\} d V_{R V E}
$$

The above equation represents a local problem defined on the RVE. For a given applied macroscopic strain, the material can be characterized if the fluctuating strain, $\left\{\varepsilon^{*}(u)\right\}$, is known. The periodicity of the strain field is ensured by imposing periodic boundary conditions on the RVE edges (figure 2); the nodal displacements on the opposite edges are set to be equal [53, 57]. equation (3) can be discretized and solved via finite element analysis as described in [46, 53-55]. 
For this purpose, equation 3 can be simplified to obtain a relation between the microscopic displacement field $\{\mathrm{D}\}$ and the force vector $\{\mathrm{f}\}$ as

$[\mathrm{K}]\{\mathrm{D}\}=\{\mathrm{f}\}$

where $[\mathrm{K}]$ is the global stiffness matrix defined as

$[\mathrm{K}]=\sum_{e=1}^{m}\left[\mathrm{k}^{e}\right],\left[\mathrm{k}^{e}\right]=\int_{Y^{e}}[\mathrm{~B}]^{T}\left[\mathrm{E}_{\mathrm{t}}\right][\mathrm{B}] d Y^{e}$

being $\sum_{e=1}^{m}(\cdot)$ the finite element assembly operator, $m$ the number of elements, [B] the straindisplacement matrix, $\left[\mathrm{E}_{\mathrm{t}}\right]$ the tangent modulus of the elastic-plastic bulk material, and $Y^{e}$ the element volume. The force vector $\{\mathrm{f}\}$ in equation 4 is expressed as

$$
\{\mathrm{f}\}=\sum_{e=1}^{m}\left\{\mathrm{f}^{e}\right\},\left\{\mathrm{f}^{e}\right\}=\int_{Y^{e}}[\mathrm{~B}]\left[\mathrm{E}_{\mathrm{t}}\right]\{\bar{\varepsilon}(u)\} d Y^{e}
$$

It is interesting to note that $\{\bar{\varepsilon}(u)\}$ in equation 6 describes the initial strain field applied to each element of the unit cell. As a result, the force vector $\{\mathrm{f}\}$ is a function not only of the applied strain but also of the properties of the solid material. Since in this work plastic deformation is required to determine fatigue strength, equation (4) can be considered as a system of non-linear equations that can be solved with the Newton-Raphson scheme. As shown in figure 3, the computational analysis is accomplished by imposing increments of macroscopic strain, as described in plastic theory $[58,59]$. While the macroscopic strain $\{\Delta \bar{\varepsilon}(u)\}$ is increased monotonically, the force vector increment is computed and replaced in equation (4) to evaluate the displacement field. During the procedure (right hand side of Fig. 3), the effective material coefficients are kept constant until the stress reaches the yield strength of the base material. The mechanical properties of the yielded elements are replaced, iteratively, with the tangent modulus 
of the elastic-plastic bulk material [58, 59]. Once the displacement field is obtained, the fluctuating strain $\left\{\Delta \varepsilon^{*}(u)\right\}$ is determined by the product of the strain-displacement matrix, [B ], and the nodal displacement vector. The increment of the microscopic strain is then determined through the equation:

$$
\{\Delta \varepsilon(u)\}=\{\Delta \bar{\varepsilon}(u)\}+\left\{\Delta \varepsilon^{*}(u)\right\}
$$

The stress field in the unit cell is updated with respect to the elastic strain, and the stress average is computed over the unit cell to attain the effective macroscopic strength as:

$$
\{\bar{\sigma}\}=\frac{1}{\left|V_{R V E}\right|} \int_{V_{R V E}}\{\sigma(u)\} d V_{R V E}
$$

The macroscopic stress, Eq. (8), represents either the yield $\left\{\bar{\sigma}_{y}\right\}$ or the ultimate $\left\{\bar{\sigma}_{u l t}\right\}$ strength of the unit cell when the stress level at any local point of the microstructure reaches respectively the yield or ultimate strength of the solid material. The whole procedure, which includes the generation of the model and its mesh, as well as the nonlinear plasticity analysis, has been implemented into ANSYS (Canonsburg, Pennsylvania, U.S.A), where the von Mises yield criterion with the associated flow rule has been considered for plasticity analysis.

Since for a high cycle fatigue failure, as it is considered in this work, the stress level is lower than the yield of the bulk material, the linear elasticity assumption holds. Hence, the fatigue strength of the unit cell can be obtained through the product of the unit cell yield strength with the ratio of the endurance limit to yield strength of the bulk material as:

$$
\left\{\bar{\sigma}_{e}\right\}=\left\{\bar{\sigma}_{y}\right\} \frac{\sigma_{e}}{\sigma_{y}}
$$

where $\sigma_{y}$ and $\sigma_{e}$ are respectively the yield strength and the endurance limit of the bulk material, and $\left\{\bar{\sigma}_{e}\right\}$ is the endurance limit of the unit cell. These properties are required to 
construct the modified Goodman diagram (Figure 1) for any type of cell topology, as shown in the next section.

\section{Cell geometries under investigation}

Square and hexagon are here selected as representative shapes of the unit cell. Since for a given cell geometry the shape of the cell has a significant effect on the static and fatigue properties of the lattice material [60-62], we examine regular and optimized shapes for square and hexagonal lattices. As shown in the flowchart of Fig. 3, the methodology to obtain the fatigue properties of the optimized cell geometry consists of three integrated parts that combine notions of design optimization and asymptotic homogenization theory. First, the shape synthesis of the unit cell is carried out to obtain a cell free of stress concentration (details given below); then its fatigue properties are computed to generate the modified Goodman diagram at given relative densities; the last step involves the minimization of the von Mises stress in the cell wall.

For square and hexagonal lattices, we study cell shapes with the following characteristics:

1. $G^{1}$ cells with sharp corners. These cells represent a conventional lattice with regular cell geometry. The fillets at the cell joints are specified by an arc with radius equal to $1 \%$ of the RVE length, which is representative of a sharp fillet resulting from a given manufacturing process. The choice of the small-arc fillet enables to obtain a realistic material distribution in a cell member [35], approximately similar to that measured through experiments $[10,11]$. These cells are named here $\mathrm{G}^{1}$, where $\mathrm{G}$ represents "geometry" and the superscript shows the degree of continuity of the geometry. As seen in figure $4, G^{1}$ cells have continuous tangent along their inner boundary profile, but the curvature at the blending points between the straight and arc geometric primitives is discontinuous.

2. $G^{1}$ cells with optimum fillet radius. The $G^{1}$ cells with sharp corners are here optimized to obtain a value of the fillet radius that reduces the effect of stress concentration. A classical 
optimization problem is formulated with the objective of minimizing the maximum value of the microscopic von Mises stress in the lattice under a given loading. The fillet radius and the thickness at the middle of the struts (Figure 4) are considered as interdependent design variables. A design constraint is set on the relative density. The problem is solved by implementing a conjugate gradient method. For given relative density and design variables a unique solution is found, as described in section 5 .

3. $G^{2}$ cell with continuous optimum curvature of the fillet. The inner profile of these unit cells are here synthesized through a methodology recently introduced to obtain lattice structures free of stress-concentration [63]. The method is based on a well-known engineering theory stating that the stress concentration due to the presence of curvature discontinuity in a component has the effect of localizing high peak of stress [64]. Thus, synthesizing the inner boundary of a cell with curves that are continuous in their curvature, i.e. $\mathrm{G}^{2}$-continous curves [65], improves the fatigue and monotonic strengths of the lattice. Furthermore, to avoid high bending moments caused by curved cell members, the cell walls can be designed to be as straight as possible, i.e. with the smallest possible curvature. The top left quadrant of Figure 3 shows the optimization formulation used in this study, while the details are given in [63]. Figure 5 (a-b) shows the parametric view of square and hexagonal cells, whose $G^{2}$ continuous profiles of their inner profiles are optimized with minimum curvature. Besides curvature minimization, a step of size optimization follows the computational analysis of the yield strength (Figure 3). Here, the wall size in the middle and corner of a cell (Figure 4) is optimized with the goal of minimizing the maximum von Mises stress. The optimum values of these variables are found through a conjugate gradient optimization method, where the density is set as a constraint.

\section{Numeric modeling}


Both $G^{1}$ and $G^{2}$ optimum cell geometries have been automatically obtained via in-house Matlab (MathWorks, Natick, Massachusetts) subroutines, which have been coupled with ANSYS (Canonsburg, Pennsylvania, U.S.A) to build, mesh, and solve the $2 \mathrm{D}$ model of the lattice material. Assuming in-plane loading conditions, a 2D eight-node element type, Plane 82, with plane strain formulation was used since it can model curved boundaries with high accuracy. Different combinations of axial and shear loadings are considered to obtain the data required to plot the failure surfaces.

The effect of the material properties on the normalized fatigue to monotonic strength ratio, $\Delta \bar{\tau}_{e} / \tau_{u l t}$, is studied by using aluminum and titanium alloys as bulk properties of the solid materials. Aluminum was selected because of its broad application for lightweight foams; Titanium is of interest because it is widely used in the aerospace, automobile, sport equipment, and biomedical sectors. Table 1 lists the material properties used in this study [66-69]. A bilinear elasto-plastic constitutive law was considered to obtain the macroscopic ultimate stress of the cellular material. An analysis of the mesh sensitivity (Figure 6) was performed to ensure the independency of the results from the mesh size. During this test, the element size of FE model was refined, especially around regions of high stress concentration, until the value of the maximum stress converged.

\section{Results}

Figures 7 and 8 show the distribution of von Mises stress (MPa) in the titanium square and hexagon with $G^{1}$ and $G^{2}$ cell boundaries under fully reversed uni-axial and shear loading conditions. The stress level significantly changes at the blending points of the $\mathrm{G}^{1}$ cells, while the stress in $\mathrm{G}^{2}$ cells is distributed uniformly along the cell struts. In addition, it can be seen that under uni-axial loading there is no stress concentration at the joints of the $\mathrm{G}^{2}$ square cell; stress 
concentration, in fact, occurs at each blending point between an arc and a straight segment, as shown in the $\mathrm{G}^{1}$ unit cell.

Figure 9 shows the yield (solid marks) and ultimate (open marks) surfaces for both $\mathrm{G}^{1}$ and $\mathrm{G}^{2}$ cells, calculated at relative density of $10 \%$. Here, the geometric parameters of the unit cells were selected to optimize the fatigue performance of the lattice under uni-axial and shear loading conditions. Figure 9 shows that $G^{2}$ cells have higher yield and ultimate strength than those of $\mathrm{G}^{1}$ cells. Also, the results show the detrimental effect of the sharp corner, i.e. small-arc fillet radius, on the strength of $G^{1}$ cells.

Figure 10 illustrates the effective yield strength of both cells under uni-axial and shear loadings as a function of the relative density. As mentioned previously, the values are extracted from the intersection of yield/ultimate surfaces with the $\bar{\sigma}_{x x}$ and $\bar{\tau}_{x y}$ axes. Figures 10 (c) and (d) show that at low relative densities, the hexagonal $\mathrm{G}^{2}$ cell has up to $50 \%$ higher yield strength in comparison to the optimum hexagonal $G^{1}$ cell; for higher relative density, on the other hand, the two unit cells have comparable yield strength. Figures 10(a) and (b) show that although both optimum $G^{1}$ and $G^{2}$ square lattices have comparable yield strengths under axial loading condition, the effect of stress concentration at the joints of the $G^{1}$ cell significantly reduces its yield strength under shear loading. Table 2 lists the yield/ultimate stresses of the $\mathrm{G}^{1}$ and $\mathrm{G}^{2}$ cells for different relative densities. Table 3 reports the fatigue to monotonic performance ratio, $\Delta \bar{\tau}_{e} / \tau_{u l t}$, of the $\mathrm{G}^{1}$ and $\mathrm{G}^{2}$ lattices made of titanium and aluminum $6061 \mathrm{~T} 6$ alloy [68, 69]. It can be observed that the numerical results for conventional lattices with small arc are close to the experimental values $(0.3$ and 0.2 respectively for $\mathrm{R}=0.1$ and $\mathrm{R}=0.5)$ reported by Côté et al [11]. Furthermore, in agreement with [11], the fatigue to ultimate monotonic stress ratio does not depend on the geometry of the unit cell, its relative density, and its material. The conformity of 


\section{Discussion}

Figures 7 and 8 show the pivot role that cell shape has on yield, ultimate and fatigue strengths of square and hexagon lattices. For each case, stress localization can be observed in $\mathrm{G}^{1}$ cells with sharp corners, an instance that reduces fatigue strength as opposed to what occurs with smooth $\mathrm{G}^{2}$ corners. As shown in Figures $7(\mathrm{a}-\mathrm{b})$ and $8(\mathrm{a}-\mathrm{b})$, the fatigue strength of a regular lattice, obtained with $\mathrm{G}^{1}$ cells with sharp corners, can be substantially improved by optimizing the unit cell variables that control the occurrence of stress concentration. For example, Table 2 shows that at relative density of $10 \%$ optimum square $\mathrm{G}^{1}$ or $\mathrm{G}^{2}$ cells have respectively $48.8 \%$ and $54 \%$ higher yield strength (fatigue strength) under fully reverse tension. This and other observations are also confirmed for dissimilar relative density by the data in Table 3, which shows the fatigue to monotonic performance ratio, $\Delta \bar{\tau}_{e} / \tau_{u l t}$, of the $\mathrm{G}^{1}$ and $\mathrm{G}^{2}$ lattices made of Ti-6Al-4V and aluminum $6061 \mathrm{~T} 6$ alloy $[68,69]$. In addition, Table 3 shows the results of the unit cells with small arc are in good agreement with the experimental values reported by Côté et al [11]. A comparison between the maximum stress (Figures 7 and 8) and failure surfaces (Figure 9) of the optimum $G^{1}$ and $G^{2}$ cells shows the benefit of a systematic cell shape optimization for fatigue 
life. The results show that $\mathrm{G}^{2}$ cells, especially the hexagonal cell, can distribute more efficiently the material within the RVE, thereby lowering the maximum stress and leveling stress localization (Figures 7 and 8). Thus, in comparison with $\mathrm{G}^{1}$ cells, the failure surfaces of $\mathrm{G}^{2}$ cells are wider, showing a higher fatigue resistance.

By comparing the failure surfaces of $G^{2}$ and $G^{1}$ cells (Figure 9), we notice that the former have a higher fatigue resistance for bending dominated lattices. In contrast for the square geometry, which is stretching dominated under uni-axial loading, $G^{2}$ cells have fatigue resistance comparable to $\mathrm{G}^{1}$ cells. Here, the stress in the cell walls is parallel to the applied load and fairly uniform (Figure 7), with maximum value mainly controlled by the thickness of the cell members. Thus, the material distribution around cell joints and the curvature discontinuity at its blending points have a minor effect on the stress regime of the lattice. On the other hand for a bending dominated lattice, the bending moment at the cell corners is maximum, which indicates that the maximum stress and fatigue resistance is controlled by the material distribution in this region. Figure 11 shows that an optimized distribution of material at the $G^{2}$ cell joints increases the fatigue strength of bending dominated lattices, i.e. lattices with hexagonal cells under in-plane pure shear and uni-axial loadings, and square cell under in-plane pure shear.

As expected, the modified Goodman diagrams of $G^{2}$ cells cover a wider range of applied alternating/mean stresses in comparison with their $\mathrm{G}^{1}$ counterparts. It should be noted that figure 11 shows the modified Goodman of lattices only for uni-axial and pure shear loadings. In practice, however, a mechanical component should resist complex load combinations, which produce multi-axial macroscopic stress states in each point. Thus for fatigue design, the modified Goodman diagrams should be obtained at critical regions subjected to a multi-axial stress state. Figure 9 illustrates the failure surfaces, which are given here for this purpose. For example, for a prescribed multi-axial stress state, such as $\sigma_{2}=0.5 \sigma_{1}$ and $\tau=0$, the distance between the origin 
and intersection points with the ultimate/yield surfaces can be chosen as yield and ultimate stresses to derive the corresponding modified Goodman diagram. Such a methodology can be of interest to find the optimized unit cells in a component made of a graded lattice material. In addition, the method can be further extended to consider the stress distribution in the unit cells close to the material boundaries and to model the effect of the grain size distribution in thin-wall cells [40]

\section{Conclusion}

A methodology based on computational mechanics has been presented to design planar lattice materials for fatigue failure. Asymptotic homogenization has been used to determine the macroscopic yield strength, ultimate strength, and endurance limit, each required to generate the modified Goodman diagrams of the lattice. A comparison with the experimental data available in literature shows a good agreement of the results.

As a case study, the methodology has been applied to investigate the effect of cell shape on the fatigue/monotonic strength of lattices with hexagonal and square cells. Failure surfaces of unit cells with their respective material distribution within the RVE and with no geometric stress concentration have been obtained. The results show that for bending dominated lattices, cells with continuous and minimum curvature geometry have superior fatigue performance than cells with shape boundaries defined by line and arc primitives. In addition in bending dominated lattice materials, unit cells with $G^{2}$ minimum curvature should be preferred over cells with arcrounded joints, especially if manufacturability is not a constraint.

\section{References}


[1] N. Fleck, V. Deshpande, M. Ashby, Micro-architectured materials: past, present and future, Proceedings of the Royal Society A: Mathematical, Physical and Engineering Science, 466 (2010) 2495.

[2] A. Vigliotti, D. Pasini, Linear multiscale analysis and finite element validation of stretching and bending dominated lattice materials, Mechanics of Materials, 46 (2012) 57 68.

[3] T. Schaedler, A. Jacobsen, A. Torrents, A. Sorensen, J. Lian, J. Greer, L. Valdevit, W. Carter, Ultralight Metallic Microlattices, Science, 334 (2011) 962-965.

[4] R.S. Kumar, D.L. McDowell, Multifunctional design of two-dimensional cellular materials with tailored mesostructure, International Journal of Solids and Structures, 46 (2009) 2871-2885.

[5] L. Mullen, R. Stamp, P. Fox, E. Jones, C. Ngo, C. Sutcliffe, Selective laser melting: A unit cell approach for the manufacture of porous, titanium, bone in-growth constructs, suitable for orthopedic applications. II. Randomized structures, Journal of Biomedical Materials Research Part B: Applied Biomaterials, 92 (2009) 178-188.

[6] L.J. Gibson, M.F. Ashby, B.A. Harley, Cellular Materials in Nature and Medicine, Cambridge University Press, New York, 2010.

[7] L. Murr, S. Gaytan, F. Medina, H. Lopez, E. Martinez, B. Machado, D. Hernandez, L. Martinez, M. Lopez, R. Wicker, Next-generation biomedical implants using additive manufacturing of complex, cellular and functional mesh arrays, Philosophical Transactions of the Royal Society A: Mathematical, Physical and Engineering Sciences, 368 (2010) 19992032. 
[8] S. Banerjee, A. Bhaskar, The applicability of the effective medium theory to the dynamics of cellular beams, International Journal of Mechanical Sciences, 51 (2009) 598608.

[9] F. Cote, V. Deshpande, N. Fleck, A. Evans, The compressive and shear responses of corrugated and diamond lattice materials, International Journal of Solids and Structures, 43 (2006) 6220-6242.

[10] F. Côté, N.A. Fleck, V.S. Deshpande, Fatigue performance of sandwich beams with a pyramidal core, International Journal of Fatigue, 29 (2007) 1402-1412.

[11] F. Côté, V.S. Deshpande, N.A. Fleck, Shear fatigue strength of a prismatic diamond sandwich core, Scripta Materialia, 56 (2007) 585-588.

[12] C. Fleck, D. Eifler, Corrosion, fatigue and corrosion fatigue behaviour of metal implant materials, especially titanium alloys, International Journal of Fatigue, 32 (2010) 929-935.

[13] N. Fleck, X. Qiu, The damage tolerance of elastic-brittle, two-dimensional isotropic lattices, Journal of the Mechanics and Physics of Solids, 55 (2007) 562-588.

[14] N. FLECK, I. QUINTANA-ALONSO, Damage Tolerance of a Sandwich Panel Containing a Cracked Square Lattice Core, Journal of Sandwich Structures and Materials, (2009).

[15] A. Wang, D. McDowell, In-plane stiffness and yield strength of periodic metal honeycombs, Journal of Engineering Materials and Technology, 126 (2004) 137-156.

[16] I. Masters, K. Evans, Models for the elastic deformation of honeycombs., Composite structures, 35 (1996) 403-422.

[17] M. Schraad, F. Harlow, A multi-field approach to modeling the dynamic response of cellular materials, International Journal of Mechanical Sciences, 48 (2006) 85-106. 
[18] S. Banerjee, A. Bhaskar, Free vibration of cellular structures using continuum modes, Journal of Sound and Vibration, 287 (2005) 77-100.

[19] M. Ruzzene, Vibration and sound radiation of sandwich beams with honeycomb truss core, Journal of Sound and Vibration, 277 (2004) 741-763.

[20] A. Wang, D. McDowell, Yield surfaces of various periodic metal honeycombs at intermediate relative density, International Journal of Plasticity, 21 (2005) 285-320.

[21] L.J. Gibson, M.F. Ashby, Cellular solids: structure and properties, Cambridge University Press, Cambridge, UK, 1999.

[22] M. Kolluri, M. Mukherjee, F. Garcia-Moreno, J. Banhart, U. Ramamurty, Fatigue of a laterally constrained closed cell aluminum foam, Acta Materialia, 56 (2008) 1114-1125.

[23] N. Kulkarni, H. Mahfuz, S. Jeelani, L.A. Carlsson, Fatigue crack growth and life prediction of foam core sandwich composites under flexural loading, Composite Structures, $59(2003) 499-505$.

[24] N. Kulkarni, H. Mahfuz, S. Jeelani, L.A. Carlsson, Fatigue failure mechanism and crack growth in foam core sandwich composites under flexural loading, Journal of reinforced plastics and composites, 23 (2004) 83.

[25] K. McCullough, N. Fleck, M. Ashby, The stress-life fatigue behaviour of aluminium alloy foams, Fatigue and Fracture of Engineering Materials and Structures, 23 (2000) 199208.

[26] F. Noble, Acoustic emission and fatigue crack growth in rigid polyurethane foam, Journal of Materials Science, 18 (1983) 1827-1835.

[27] F. Noble, J. Lilley, Fatigue crack growth in polyurethane foam, Journal of Materials Science, 16 (1981) 1801-1808. 
[28] M. Burman, Fatigue crack initiation and propagation in sandwich structures, PhD theses. Department of Aeronautics, Royal Institute of Technology, Stockholm, Sweden, (1998).

[29] O. Olurin, K. McCullough, N. Fleck, M. Ashby, Fatigue crack propagation in aluminium alloy foams, International Journal of Fatigue, 23 (2001) 375-382.

[30] K. McCullough, N. Fleck, M. Ashby, Uniaxial stress-strain behaviour of aluminium alloy foams, Acta Materialia, 47 (1999) 2323-2330.

[31] C. Motz, O. Friedl, R. Pippan, Fatigue crack propagation in cellular metals, International Journal of Fatigue, 27 (2005) 1571-1581.

[32] J.-S. Huang, S.-Y. Liu, Fatigue of honeycombs under in-plane multiaxial loads, Materials Science and Engineering: A, 308 (2001) 45-52.

[33] J.-S. Huang, S.-Y. Liu, Fatigue of isotropic open-cell foams under multiaxial loads, International Journal of Fatigue, 23 (2001) 233-240.

[34] J.S. Huang, J.Y. Lin, Fatigue of cellular materials, Acta Materialia, 44 (1996) 289-296.

[35] A. Simone, L. Gibson, Effects of solid distribution on the stiffness and strength of metallic foams, Acta Materialia, 46 (1998) 2139-2150.

[36] T. Nicholas, J. Zuiker, On the use of the Goodman diagram for high cycle fatigue design, International Journal of Fracture, 80 (1989) 219-235.

[37] A. Dancygier, D. Yankelevsky, A. Nimrod, W. Benson, H. Shibata, K. Tokaji, T. Ogawa, H. Shiota, Microstructure dependence of fatigue strength and fatigue crack propagation in titanium aluminide, International Journal of Fatigue, 18 (1996) 119-125.

[38] G. Lütjering, J. Williams, A. Gysler, Microstructure and mechanical properties of titanium alloys, Microstructure and Properties of Materials, 2 (2000) 1-74. 
[39] M. Li, F. Guiu, Subcritical fatigue crack growth in alumina--I. Effects of grain size, specimen size and loading mode, Acta metallurgica et materialia, 43 (1995) 1859-1869.

[40] O.C. Zienkiewicz, R.L. Taylor, The finite element method for solid and structural mechanics, Butterworth-Heinemann, Burlington, US, 2005.

[41] M.S.A. Elsayed, D. Pasini, Analysis of the elastostatic specific stiffness of 2D stretching-dominated lattice materials, Mechanics of Materials, 42 (2010) 709-725.

[42] L. Gibson, M. Ashby, Cellular solids: structure and properties, Cambridge Univ Pr, 1999.

[43] R. Kumar, D. McDowell, Generalized continuum modeling of 2-D periodic cellular solids, International Journal of Solids and Structures, 41 (2004) 7399-7422.

[44] R.M. Christensen, Mechanics of cellular and other low-density materials, International Journal of Solids and Structures, 37 (2000) 93-104.

[45] J. Chen, M. Huang, Fracture analysis of cellular materials: a strain gradient model, Journal of the Mechanics and Physics of Solids, 46 (1998) 789-828.

[46] B. Hassani, E. Hinton, A review of homogenization and topology opimization I I-analytical and numerical solution of homogenization equations, Computers \& Structures, 69 (1998) 719-738.

[47] B. Hassani, E. Hinton, A review of homogenization and topology optimization I-homogenization theory for media with periodic structure, Computers \& Structures, 69 (1998) 707-717.

[48] W.-X. Wang, D. Luo, Y. Takao, K. Kakimoto, New solution method for homogenization analysis and its application to the prediction of macroscopic elastic constants of materials with periodic microstructures, Computers \& Structures, 84 (2006) 991-1001. 
[49] Z. Fang, W. Sun, J. Tzeng, Asymptotic homogenization and numerical implementation to predict the effective mechanical properties for electromagnetic composite conductor, Journal of Composite Materials, 38 (2004) 1371.

[50] E. Andrews, G. Gioux, P. Onck, L. Gibson, Size effects in ductile cellular solids. Part II: experimental results, International Journal of Mechanical Sciences, 43 (2001) 701-713.

[51] W. Warren, E. Byskov, Three-fold symmetry restrictions on two-dimensional micropolar materials, European Journal of Mechanics-A/Solids, 21 (2002) 779-792.

[52] A. Vigliotti, D. Pasini, Stiffness and strength of tridimensional periodic lattices, Computer methods in applied mechanics and engineering, 229-232 (2012) 27-43.

[53] S. Hollister, N. Kikuchi, A comparison of homogenization and standard mechanics analyses for periodic porous composites, Computational Mechanics, 10 (1992) 73-95.

[54] J. Guedes, N. Kikuchi, Preprocessing and postprocessing for materials based on the homogenization method with adaptive finite element methods, Computer methods in applied mechanics and engineering, 83 (1990) 143-198.

[55] S. Jansson, Homogenized nonlinear constitutive properties and local stress concentrations for composites with periodic internal structure, International Journal of Solids and Structures, 29 (1992) 2181-2200.

[56] K. Matsui, K. Terada, K. Yuge, Two-scale finite element analysis of heterogeneous solids with periodic microstructures, Computers \& Structures, 82 (2004) 593-606.

[57] B. Hassani, A direct method to derive the boundary conditions of the homogenization equation for symmetric cells, Communications in numerical methods in engineering, 12 (1996) 185-196.

[58] R. Cook, D. Malkus, M. Plesha, R. Witt, Concepts and applications of finite element analysis. 2002, in, Wiley, New York. 
[59] K.J. Bathe, Finite element procedures, Prentice hall Englewood Cliffs, NJ, 1996.

[60] F. Lipperman, M. Ryvkin, M. Fuchs, Design of crack-resistant two-dimensional periodic cellular materials, JOURNAL OF MECHANICS OF MATERIALS AND STRUCTURES http://www. jomms. org, (2009) 441.

[61] H. Harders, K. Hupfer, J. Rosler, Influence of cell wall shape and density on the mechanical behaviour of 2D foam structures, Acta materialia, 53 (2005) 1335-1345.

[62] S. Banerjee, D. Bhattacharyya, Optimal design of sandwich panels made of wood veneer hollow cores, Composites Science and Technology, (2010).

[63] E. Masoumi Khalil Abad, S. Arabnejad Khanoki, D. Pasini, SHAPE DESIGN OF PERIODIC CELLULAR MATERIALS UNDER CYCLIC LOADING, in: ASME 2011 International Design Engineering Technical Conferences \& Computers and Information in Engineering Conference IDETC/CIE 2011, Washington 2011.

[64] H. Neuber, Theory of notch stresses: Principles for Exact Calculation of Strength with Reference to Structural Form and Material, 2nd ed., United States Atomic Energy Commission, Washington, 1961.

[65] C.P. Teng, S. Bai, J. Angeles, Shape Synthesis in Mechanical Design., Acta Polytechnica, 47 (2008) 56-62.

[66] J. Case, L. Chilver, C.T.F. Ross, Strength of Materials and Structures (4th Edition), in, Elsevier, 1999.

[67] P. Ducheyne, D. Kohn, T. Smith, Fatigue properties of cast and heat treated Ti---6Al--4V alloy for anatomic hip prostheses, Biomaterials, 8 (1987) 223-227.

[68] T. Nicholas, Tensile testing of materials at high rates of strain, Experimental Mechanics, 21 (1981) 177-185.

[69] U.S.D.o. Defense, Aluminum and aluminum alloys, US Dept. of Defense, 1966. 


\section{List of Figures and Tables}

Table 1. Material properties of bulk solid materials

Table 2. Yield and ultimate strength of $G^{1}$ and $G^{2}$ unit cells for square and hexagonal lattices

Table 3. Fatigue to monotonic performance ratio, ${ }^{\Delta \bar{\tau}_{e}} / \tau_{u t t}$, for G1 and G2 lattices made of Ti-6Al-4V and Al $6061 \mathrm{T6}$ (material properties in Table 1) at given relative densities.

Figure 1. Fatigue design diagrams showing the relation between alternating stress and mean stress for a number of cycles.

Figure 2. Periodic boundary conditions for a pair of nodes located on the opposite surfaces, $A^{-}$and $A^{+}$, of the RVE

Figure 3. Flowchart of the design methodology. For a given cell geometry, shape synthesis is coupled with computational analysis follow by size optimization. The goal of the first step is to smooth the transitions between the geometric primitives defining the cell inner boundaries, thereby reducing stress localization. In the second module, the effective strength properties of the lattice are determined through asymptotic homogenization theory. The third step involves the cell size optimization to reduce at minimum the maximum von Mises stress in the cell wall.

Figure 4. Schematic views of: (a) $G^{1}$ square unit cell; (b) $G^{1}$ hexagonal unit cell

Figure 5. Schematic views of: (a) $G^{2}$ continuous square cell; (b) $G^{2}$ continuous hexagonal cell; (c) Parameterization of the inner profile of a unit cell portion.

Figure 6. Mesh sensitivity showing the independency of the results from the mesh size.

Figure 7. Von Mises stress (MPa) distribution in hexagonal (a) and square (b) unit cells made out of Ti6Al-4V. Lattices under fully reversed uni-axial loading, defined by: $\mathrm{G}^{1}$ cell with small arc (left), optimum $\mathrm{G}^{1}$ cell (middle), and optimum $\mathrm{G}^{2}$ cell (right). 
Figure 8. Von Mises stress (MPa) distribution in hexagonal (a) and square (b) unit cells made out of Ti6Al-4V. Lattices under fully reversed pure shear, defined by: $G^{1}$ cell with small arc (left), optimum $G^{1}$ cell (middle), and optimum $\mathrm{G}^{2}$ cell (right).

Figure 9. Yield and ultimate surfaces of Ti-6Al-4V square and hexagonal unit cells for relative density of $10 \%$. Projection of yield and ultimate surfaces of the $\mathrm{G}^{1}$ and $\mathrm{G}^{2}$ square cells in the planes: $\bar{\sigma}_{x x}-\bar{\sigma}_{y y}$ (a), $\bar{\sigma}_{x x}-\bar{\tau}_{x y}(\mathrm{~b}), \bar{\sigma}_{x x}-\bar{\sigma}_{y y}(\mathrm{c}), \bar{\sigma}_{x x}-\bar{\tau}_{x y}$ (d).

Figure 10. Effective yield strength of the square and hexagonal unit cells under uni-axial and shear loading as a function of relative density. Yield strength for square unit cell under uni-axial (a) and shear loading respectively (b); (c) and (d) pertain to the hexagonal cell.

Figure 11. Modified Goodman diagram for Ti-6Al-4V square and hexagonal unit cells at given relative densities. $G^{1}$ and $G^{2}$ square under uni-axial loading (a), and shear loading condition (b); $G^{1}$ and $G^{2}$ hexagon under uni-axial loading (c), and shear loading (d). 
Table 1. Material properties of bulk solid materials

\begin{tabular}{|c|c|c|c|c|c|c|}
\hline & $\begin{array}{c}\text { Young's } \\
\text { Modulus }\left(E_{s}\right)\end{array}$ & $\begin{array}{c}\text { Poisson's ratio } \\
(v)\end{array}$ & $\begin{array}{c}\text { Yield } \\
\text { strength }\end{array}$ & $\begin{array}{c}\text { Ultimate } \\
\text { tensile } \\
\text { strength }\end{array}$ & $\begin{array}{c}\text { Elongation } \\
\text { endurance limit }\end{array}$ & $\begin{array}{c}\text { Fatigue fracture } \\
(\%)\end{array}$ \\
\hline $\begin{array}{c}\text { Ti-6Al-4V } \\
{[67,68]}\end{array}$ & $110 \mathrm{GPa}$ & 0.3 & $901 \mathrm{MPa}$ & $984 \mathrm{MPa}$ & $486 \mathrm{MPa}$ & 8.9 \\
\hline $\begin{array}{c}\text { Aluminum } \\
6061 \\
{[69,70]}\end{array}$ & $69 \mathrm{GPa}$ & 0.3 & $276 \mathrm{MPa}$ & $310 \mathrm{MPa}$ & $158 \mathrm{MPa}$ & 12 \\
\hline
\end{tabular}


Table 2. Yield and ultimate strength of $\mathrm{G}^{1}$ and $\mathrm{G}^{2}$ unit cells for square and hexagonal lattices.

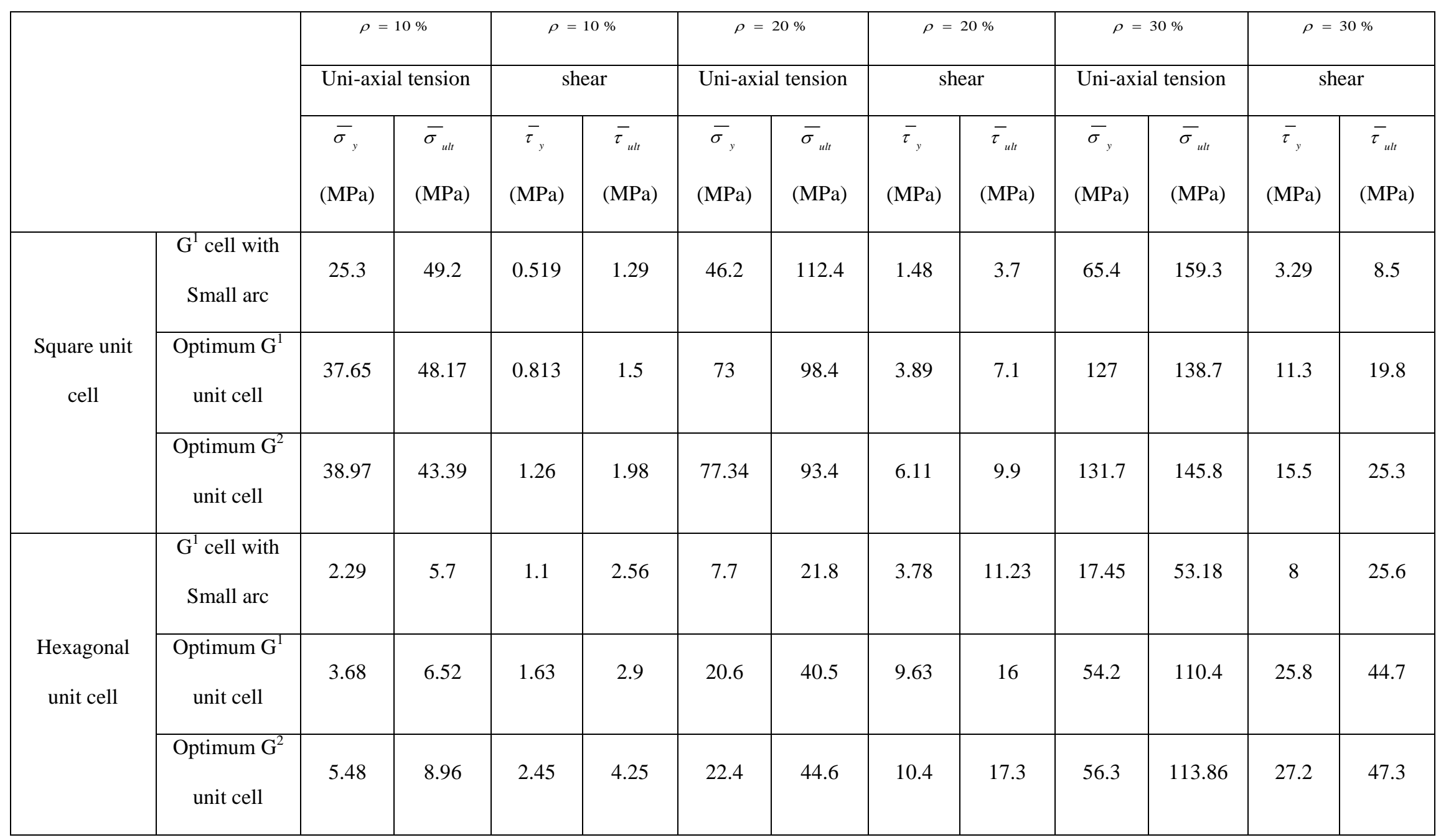


Table 3. Fatigue to monotonic performance ratio, $\Delta \bar{\tau}_{e} / \tau_{u l t}$, for $\mathrm{G}^{1}$ and $\mathrm{G}^{2}$ lattices made of Ti-6Al-4V and Al $6061 \mathrm{T6}$ (material properties in Table 1) at given relative densities.

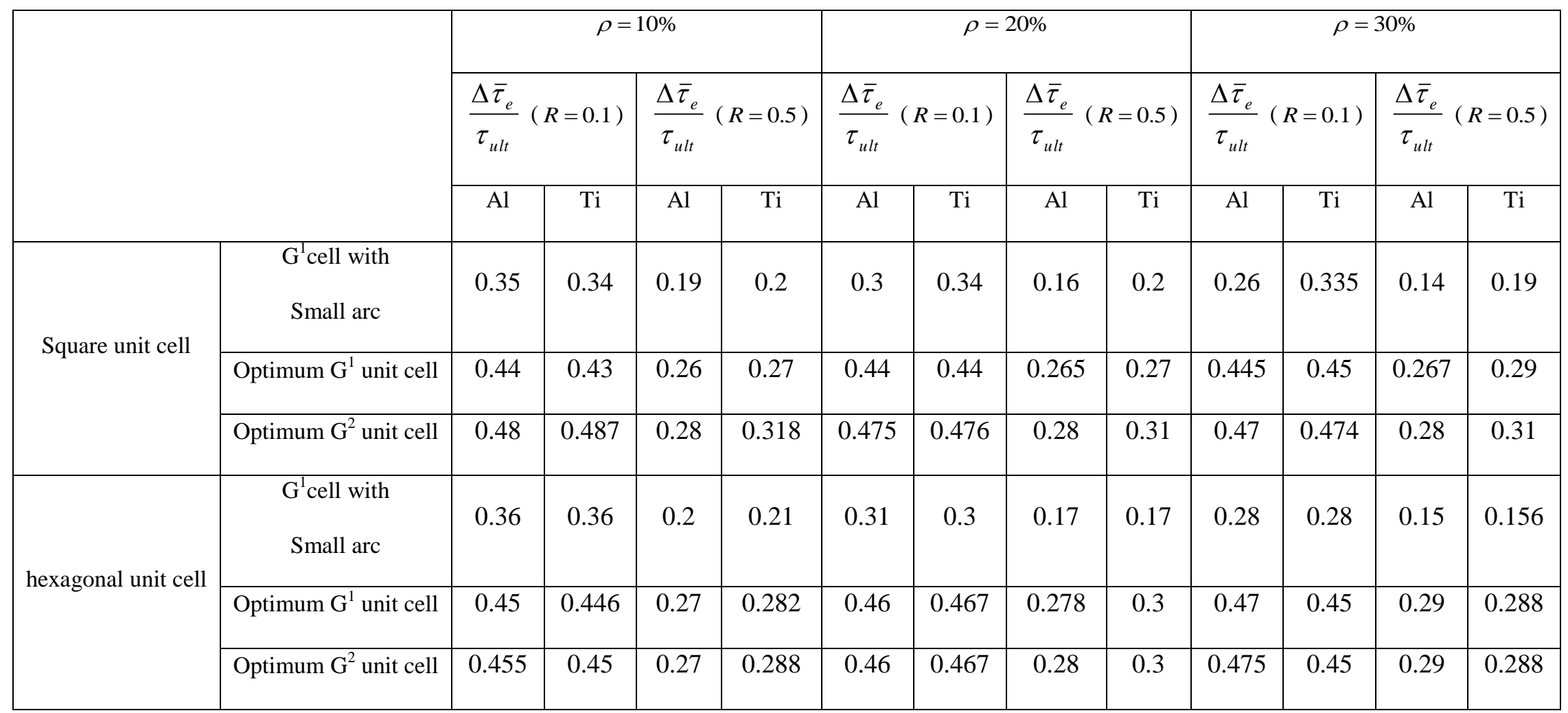




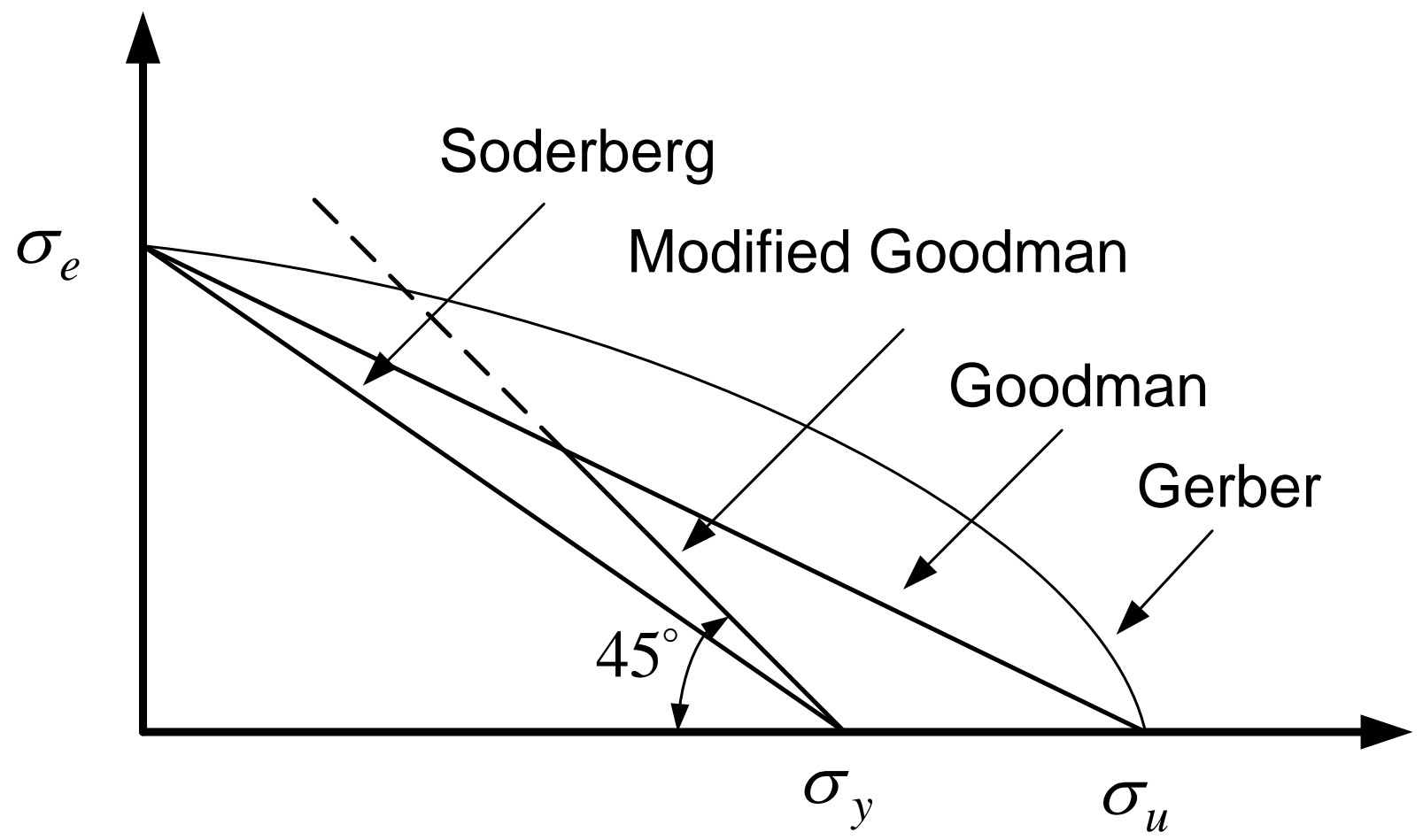

Figure 1. Fatigue design diagrams showing the relation between alternating stress and mean stress for a given number of cycles. 


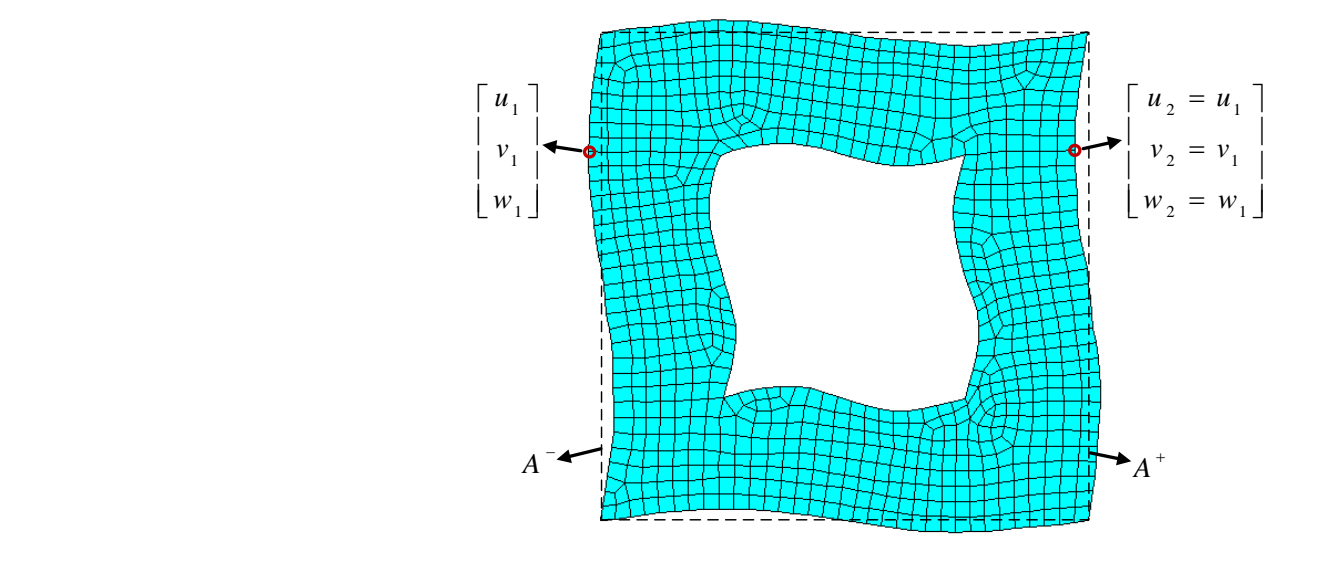

Figure 2. Periodic boundary conditions for a pair of nodes located on the opposite surfaces, $A^{-}$and $A^{+}$, of the RVE.

Figure 2 (1)

(1)

\section{Eure 2} (1)

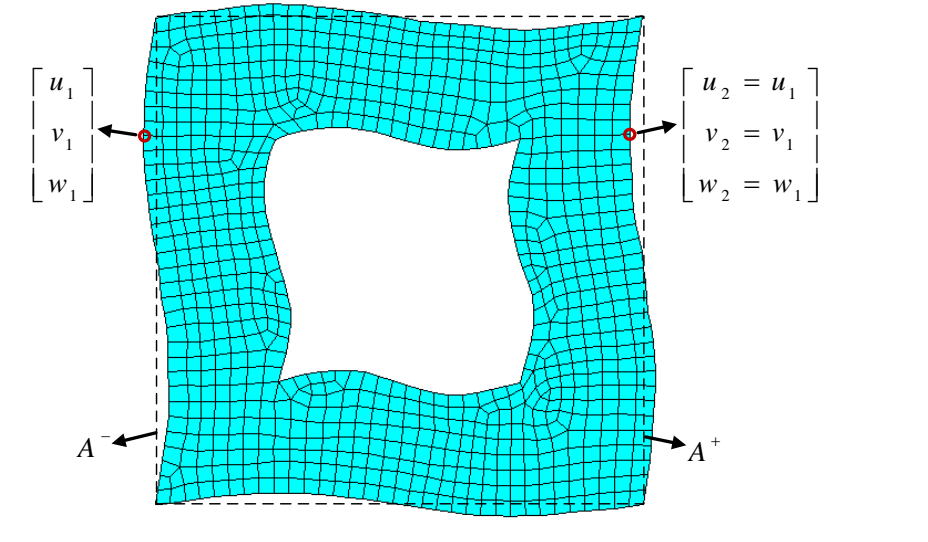

(1)

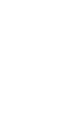




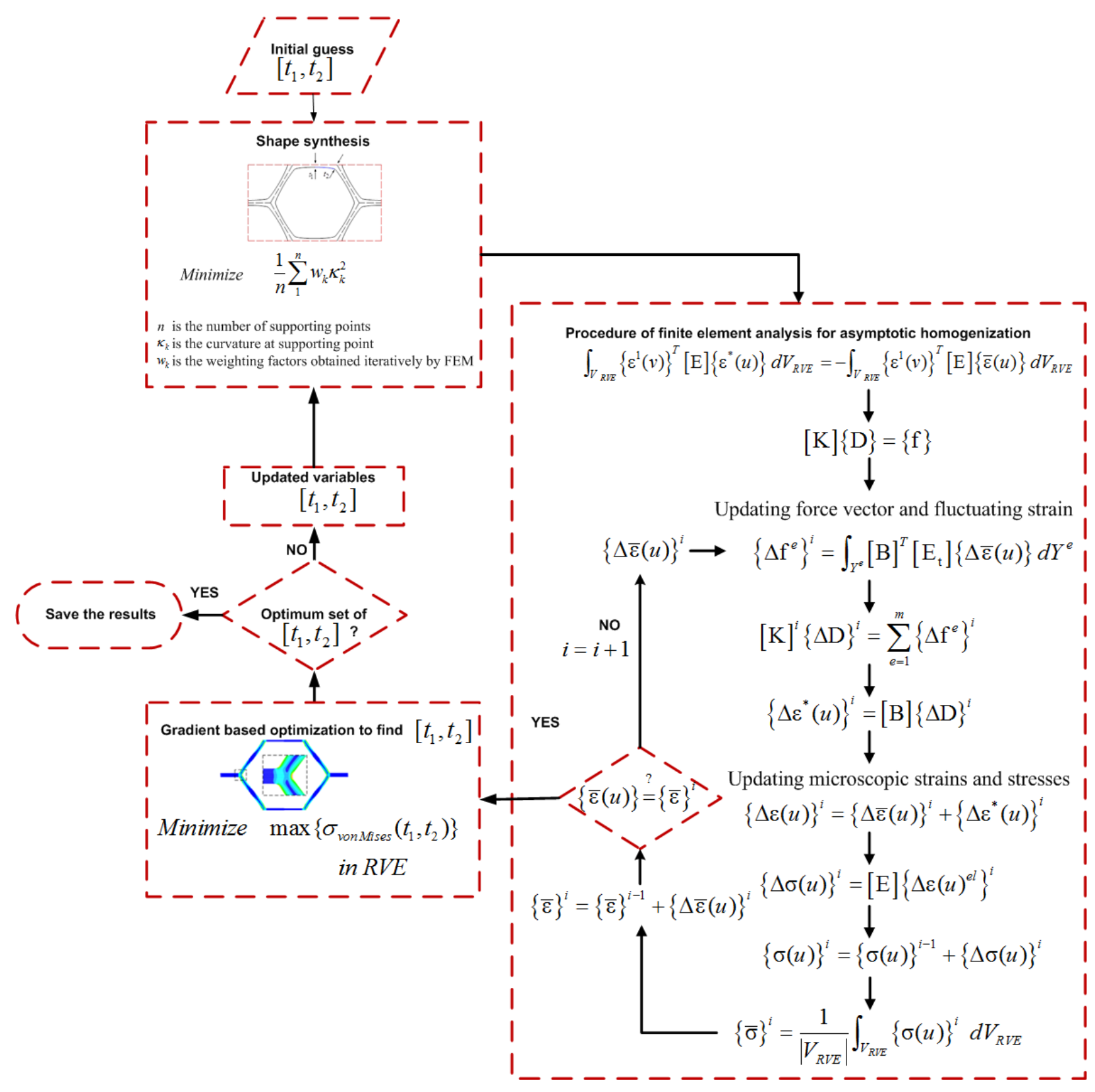

Figure 3. Flowchart of the design methodology. For a given cell geometry, shape synthesis is coupled with computational analysis follow by size optimization. The goal of the first step is to smooth the transitions between the geometric primitives defining the cell inner boundaries, thereby reducing stress localization. In the second module, the effective strength properties of the lattice are determined through asymptotic homogenization theory. The third step involves the cell size optimization to reduce at minimum the maximum von Mises stress in the cell wall. 
Figure 4

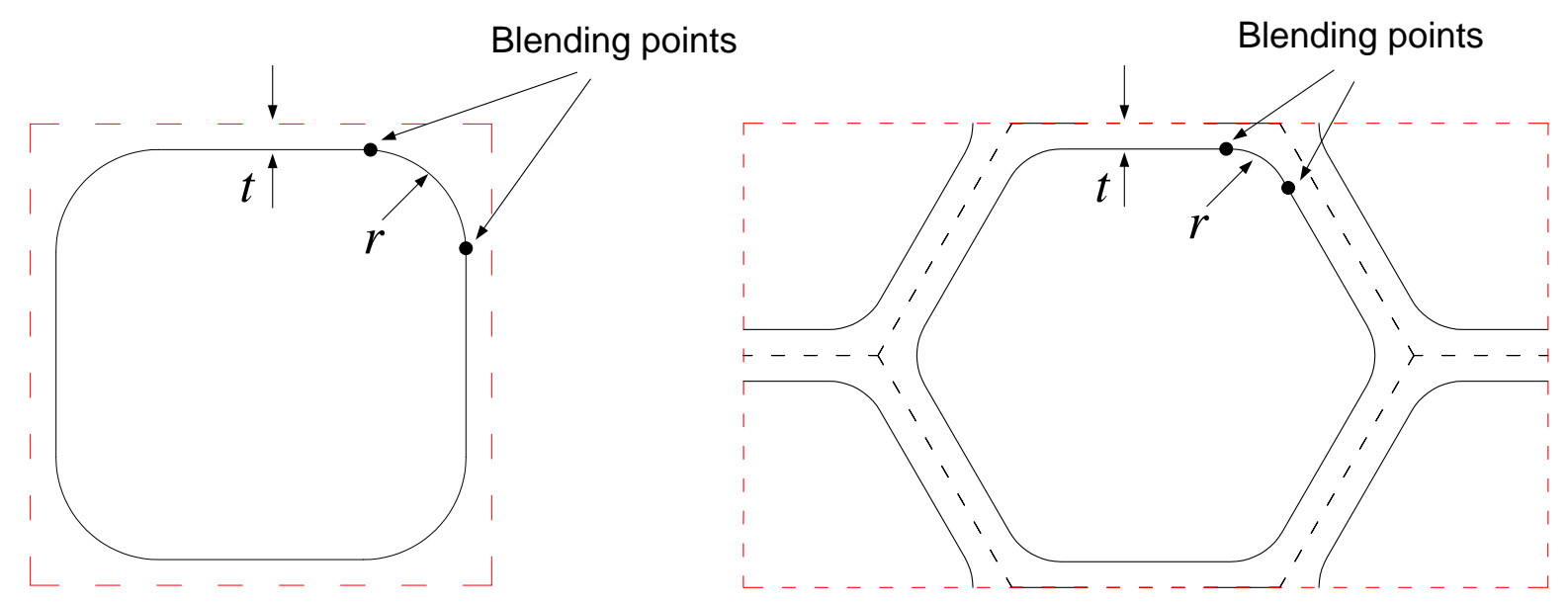

Figure 4. Schematic views of: (a) $G^{1}$ square unit cell; (b) $G^{1}$ hexagonal unit cell 
Figure 5

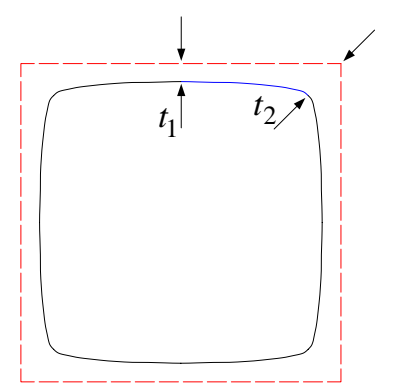

(a)

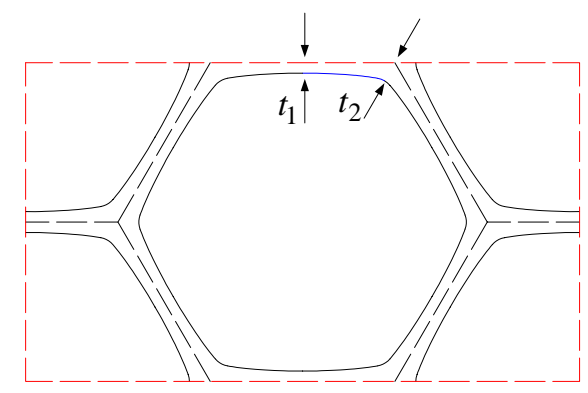

(b)

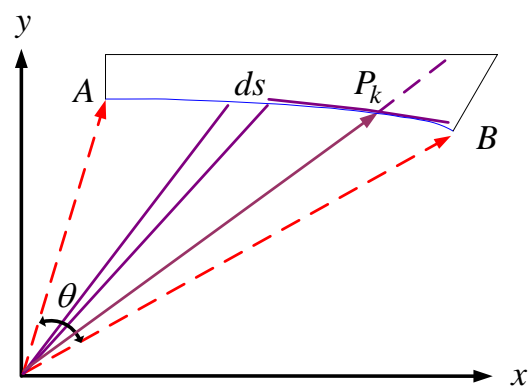

(c)

Figure 5. Schematic views of: (a) $G^{2}$ continuous square cell; (b) $G^{2}$ continuous hexagonal cell; (c) Parameterization of the inner profile of a unit cell portion. 


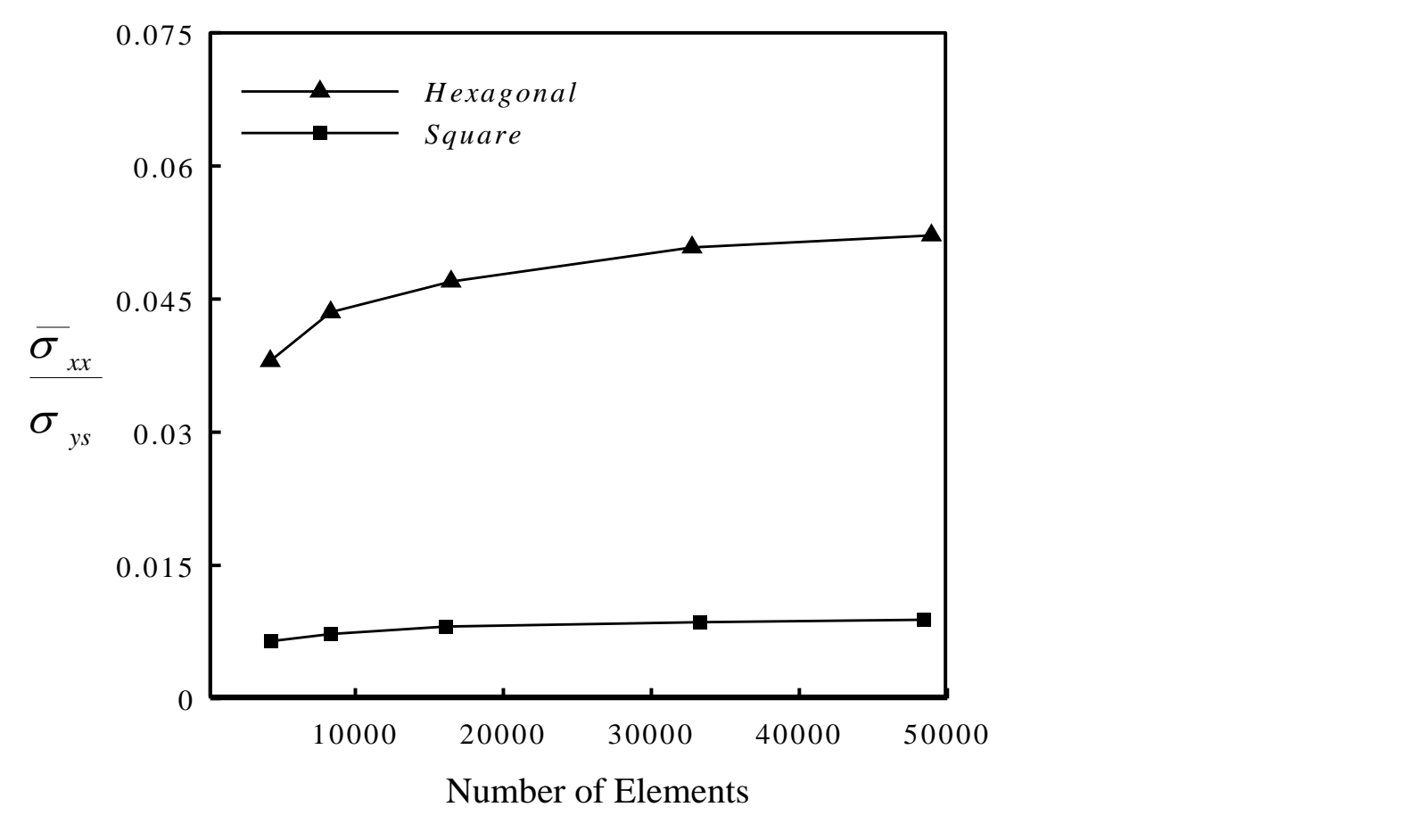

Figure 6. Mesh sensitivity showing the independency of the results from the mesh size.

Figure 6. Mesh sensitivity showing the independency of the results from the mesh size.

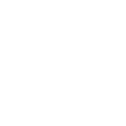

Figure 6

6

umber of Elements

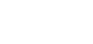

(1)

列

.

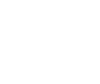
(n)

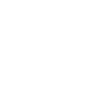
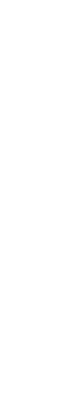


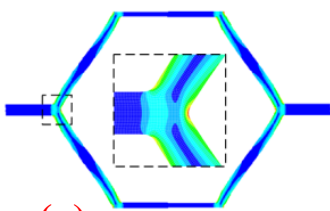

(a)

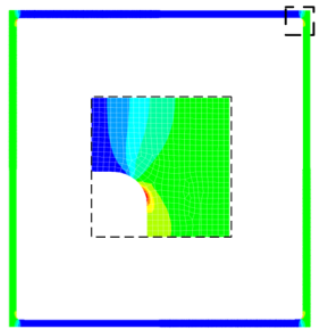

(b)
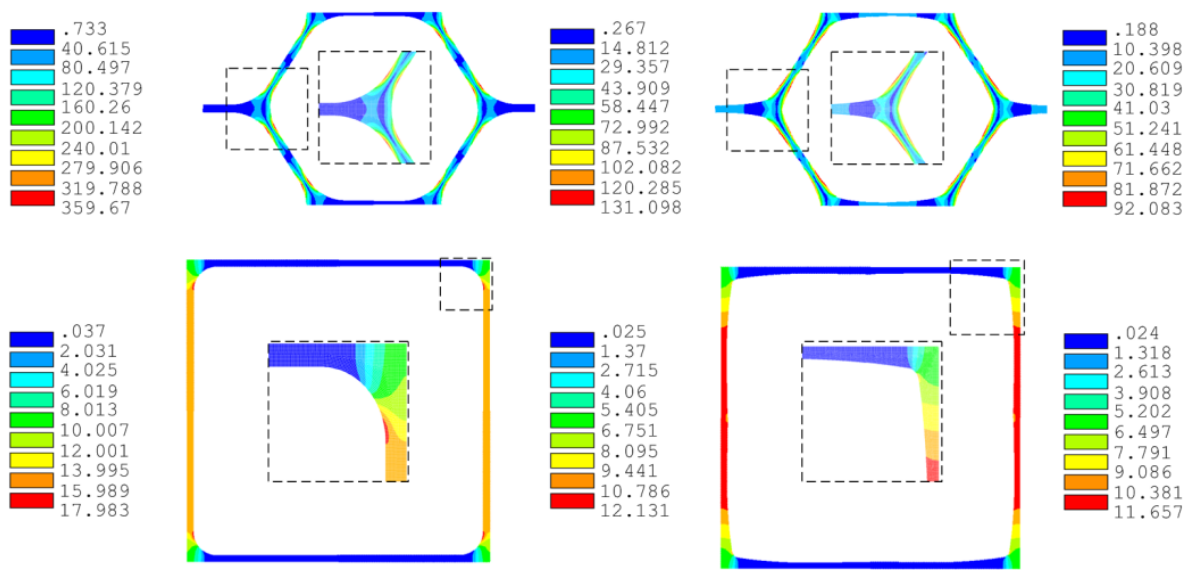

Figure 7. Von Mises stress (MPa) distribution in hexagonal (a) and square (b) unit cells made out of Ti-6Al-4V . Lattices under fully reversed uni-axial loading, defined by: $\mathrm{G}^{1}$ cell with small $\operatorname{arc}\left(\right.$ left), optimum $\mathrm{G}^{1}$ cell (middle), and optimum $\mathrm{G}^{2}$ cell (right). 
Figure 8
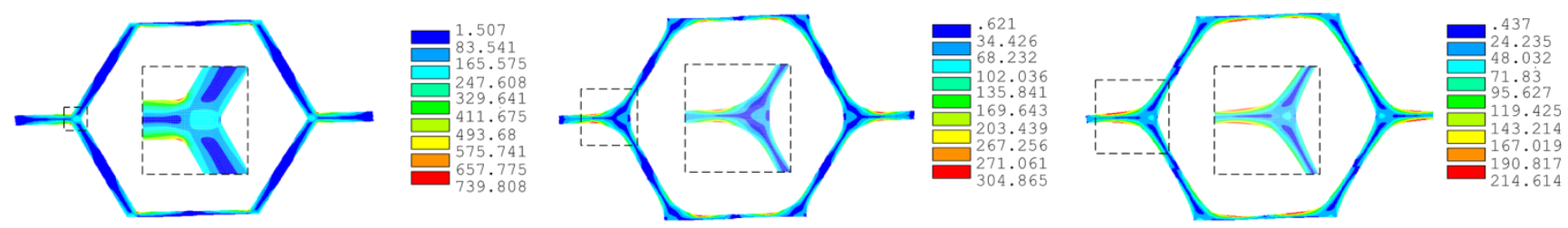

(a)
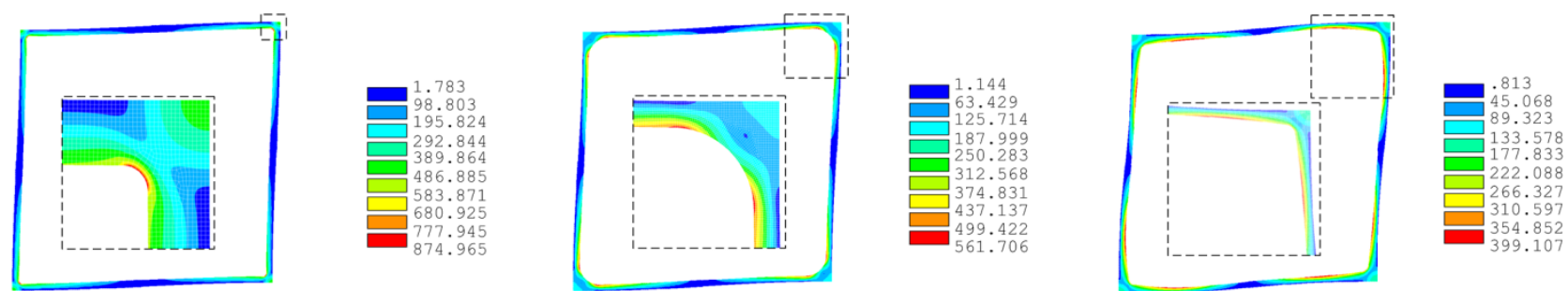

(h)

Figure 8. Von Mises stress (MPa) distribution in hexagonal (a) and square (b) unit cells made out of Ti6Al-4V. Lattices under fully reversed pure shear, defined by: $\mathrm{G}^{1}$ cell with small arc (left), optimum $\mathrm{G}^{1}$ cell (middle), and optimum $\mathrm{G}^{2}$ cell (right). 

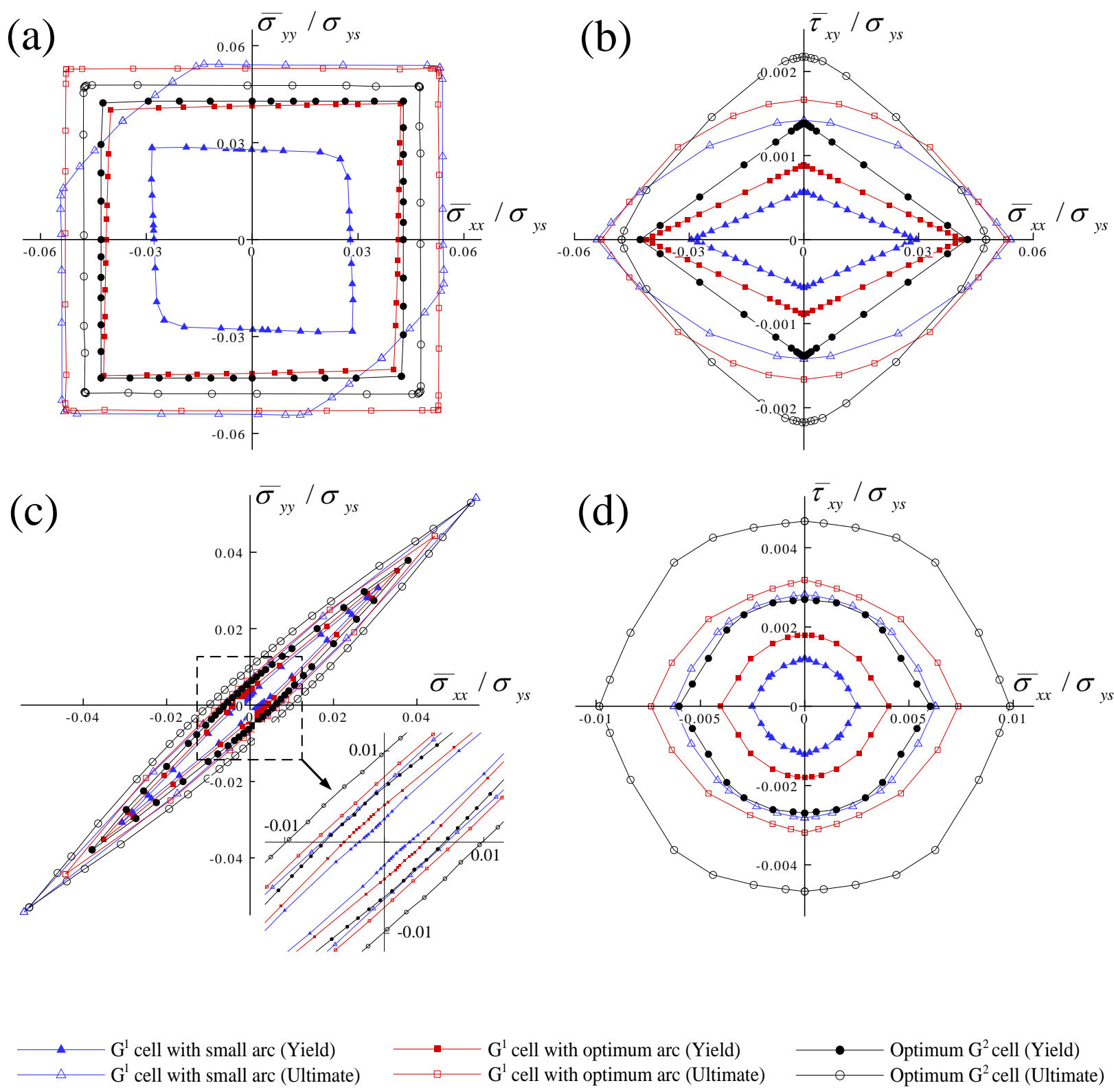

Figure 9. Yield and ultimate surfaces of Ti-6Al-4V square and hexagonal unit cells for relative density of $10 \%$. Projection of yield and ultimate surfaces of $G^{1}$ and $G^{2}$ square cells in the planes: $\bar{\sigma}_{x x}-\bar{\sigma}_{y y}$ (a), $\bar{\sigma}_{x x}-\bar{\tau}_{x y}(\mathrm{~b}), \bar{\sigma}_{x x}-\bar{\sigma}_{y y}(\mathrm{c}), \bar{\sigma}_{x x}-\bar{\tau}_{x y}(\mathrm{~d})$ 

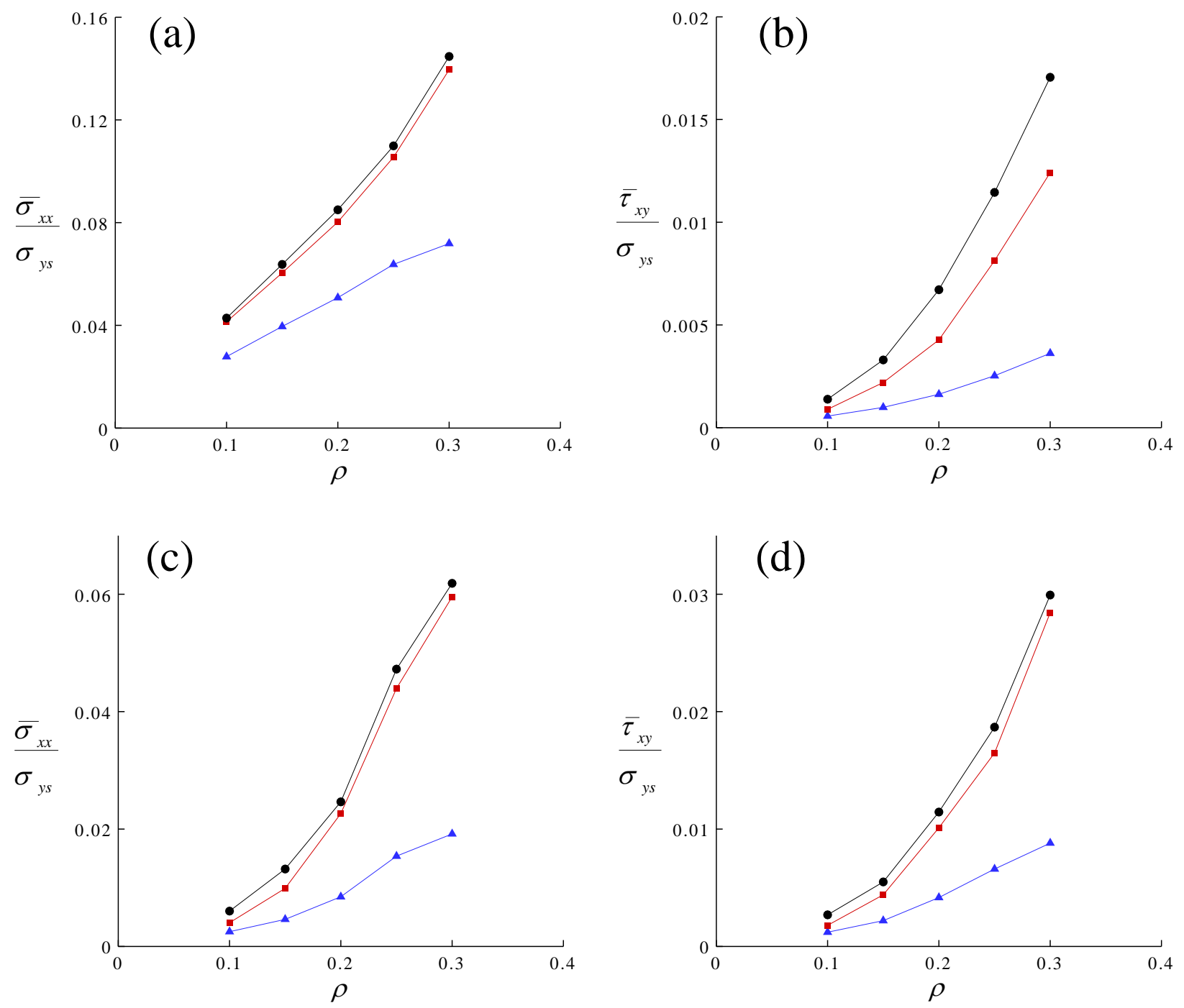

$\_\mathrm{G}^{1}$ cell with small arc

$\longrightarrow \mathrm{G}^{1}$ cell with optimum arc

- Optimum $\mathrm{G}^{2}$ cell

Figure 10. Effective yield strength of the square and hexagonal unit cells under uni-axial and shear loading as a function of relative density. Yield strength for square cell under uni-axial (a) and shear loading respectively (b); (c) and (d) pertain to the hexagonal cell. 

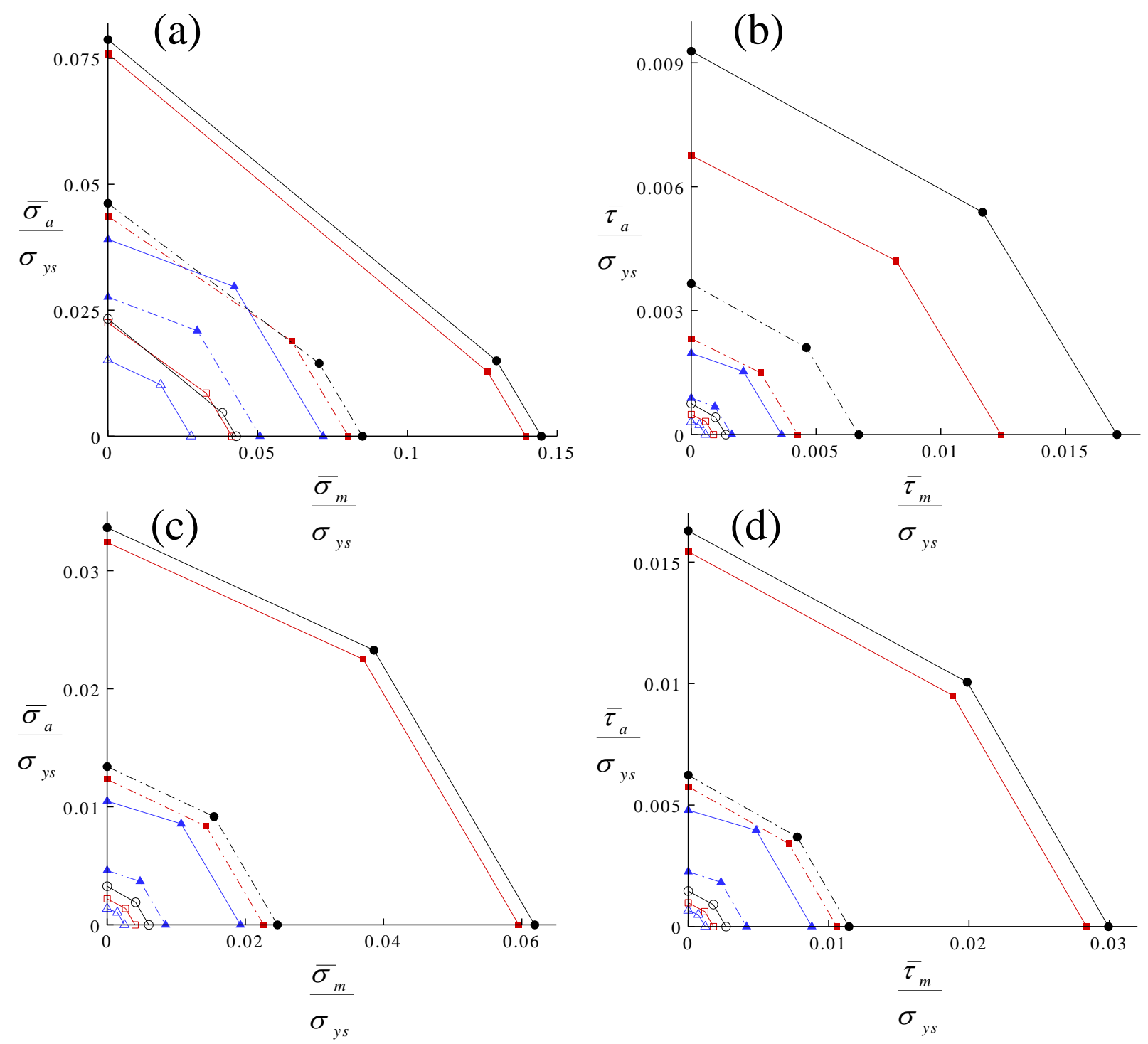

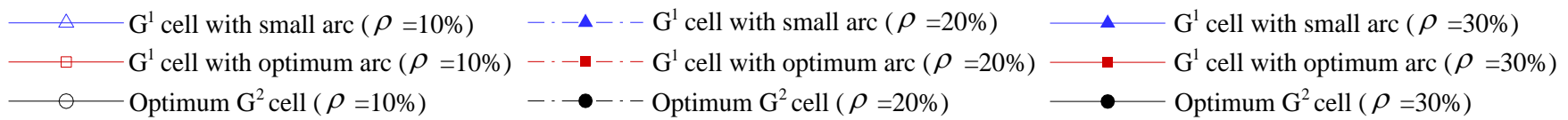

Figure 11. Modified Goodman diagram for Ti-6Al-4V square and hexagonal unit cells at given relative densities. $G^{1}$ and $G^{2}$ square under uni-axial loading (a), and shear loading condition (b); $G^{1}$ and $G^{2}$ hexagon under uni-axial loading (c), and shear loading (d). 